\title{
Effect of community based management in failure to thrive: randomised controlled trial
}

\author{
Charlotte M Wright, Jane Callum, Eileen Birks, Stephen Jarvis
}

\begin{abstract}
Objective: To evaluate the effectiveness of a health visitor led intervention for failure to thrive in children under 2 years old.

Design: Controlled trial, randomised by primary care practice.

Setting: Newcastle upon Tyne health district.

Intervention: Structured health visitor management, with dietetic, paediatric, and social work input as required.

Subjects: 229 children (120 in intervention practices and 109 in control practices) were identified as failing to thrive by population screening during the first 2 years of life. Follow up was by home visit of a research nurse and review of the childrens' records at age 3 years.

Main outcome measures: Follow up weight and height and number of routinely collected weights. Results: 95 of the 97 families offered intervention completed at least the initial assessment. At follow up, $187(82 \%)$ records were reviewed, and these suggested that $15(16 \%)$ controls were lost to follow up immediately after the screening weight was taken compared with only one child in the intervention group. In the 134 (58\%) families who consented to home visits, children in the intervention group were significantly heavier and taller and were reported to have better appetites than childen in the control group, although both groups were equally satisfied by the services they had received. When the children were last weighed, $91(76 \%)$ in the intervention group had recovered from their failure to thrive compared with $60(55 \%)$ in the control group $(\mathrm{P}<0.001)$.

Conclusion: In failure to thrive, health visitor intervention, with limited specialist support, can significantly improve growth compared with conventional management.
\end{abstract}

\section{Introduction}

Failure to thrive is a common problem in primary care and paediatric practice. It usually results from a range and combination of dietary, organic, and social factors, leading to undernutrition. ${ }^{1}$ Failure to thrive is therefore not ideally suited to hospital based management. Slow weight gain in infancy has been associated with subsequent stunting, ${ }^{2}$ developmental delay, ${ }^{3}$ and even heart disease in adulthood. ${ }^{4}$ There have been few successful trials of intervention, however, although two non-randomised studies have suggested that a specialist multidisciplinary team with an emphasis on increased energy intake ${ }^{5}$ and home based nurtural support $t^{6}$ may improve growth outcomes.

Health visitors provide universal support and surveillance for families with preschool children, and are usually the first to identify children failing to thrive. However, conventional management in hospital usually makes no further use of the health visitor's knowledge of the family and contacts. We developed an intervention which uses health visitors as key workers, and compared its effectiveness with conventional management.

\section{Subjects and methods}

\section{Subjects}

Children were identified using a screening programme that required a minimum of two weights to be entered on the district child health computer for each infant: a baseline weight at the $6-8$ week check and a later weight submitted by the health visitor, usually when the infant was between 9 and 18 months old. The computer identified children as failing to thrive if the second weight standard deviation score $\left(\mathrm{SDS}_{2}\right)$ showed a fall from the baseline weight $\left(\mathrm{SDS}_{1}\right)$ at 6 weeks, after adjustment for regression to the mean using the thrive index method (defined as $\left.\mathrm{SDS}_{2}-\mathrm{SDS}_{1} \times 0.65\right){ }^{7}$ The screening threshold used was a fall of $1.26 \mathrm{SD}$, equivalent to a centile shift from the 50th to between the 10th and 3rd centile, which identifies the $5 \%$ of children with slowest gain.?

Recruitment to the study began in October 1991 and continued for 2 years. All children resident in Newcastle and born after October 1990 were eligible for inclusion. When a pair of twins screened in, only the first twin identified was included, otherwise there were no exclusions. All data were checked by project staff before cases were included. Compliance with the screening programme by health visitors was not universal, and during the study period 229 children were identified as failing to thrive, a screening rate of $3 \%$ instead of the $5 \%$ expected (fig).

\section{Allocation to treatment}

Twenty of the 38 primary care teams in Newcastle upon Tyne were randomly allocated by toss of a coin to take part in the intervention. Each team comprised 1-3 health visitors who dealt with $30-150$ births annually. All children identified in these practices were offered intervention, and those in the remaining practices constituted controls.

\section{Intervention}

The intervention was developed by the Parkin project, a multidisciplinary group initially comprising a liaison health visitor and a research paediatrician both of whom worked on the project for half a working week, and a paediatric dietician who worked half a day per fortnight. The staff provided introductory training for health visitors in the intervention practices as well as twice yearly sessions thereafter.

In the intervention practices 120 cases of failure to thrive were identified; 23 had no additional input because they had recovered to above the screening threshold before identification (figure). Of the 97 eligible children remaining, 95 (98\%) received a standardised health visitor assessment at a mean age of 15.6

\author{
Department of \\ Child Health, \\ Newcastle \\ University, Donald \\ Court House, \\ Gateshead \\ NE8 1EB \\ Charlotte M Wright, \\ first assistant in \\ community child \\ health \\ Jane Callum, \\ research nurse \\ Stephen Jarvis, \\ Donald Court \\ professor of \\ community child \\ health \\ Parkin Service, \\ Newcastle City \\ Health Trust, \\ Arthur's Hill Clinic, \\ Douglas Terrace, \\ Newcastle upon \\ Tyne NE4 6BT \\ Eileen Birks, \\ liaison health visitor \\ Correspondence to: \\ Dr Wright \\ c.m.wright@ncl.ac.uk
}

BMJ 1998;317:571-4 


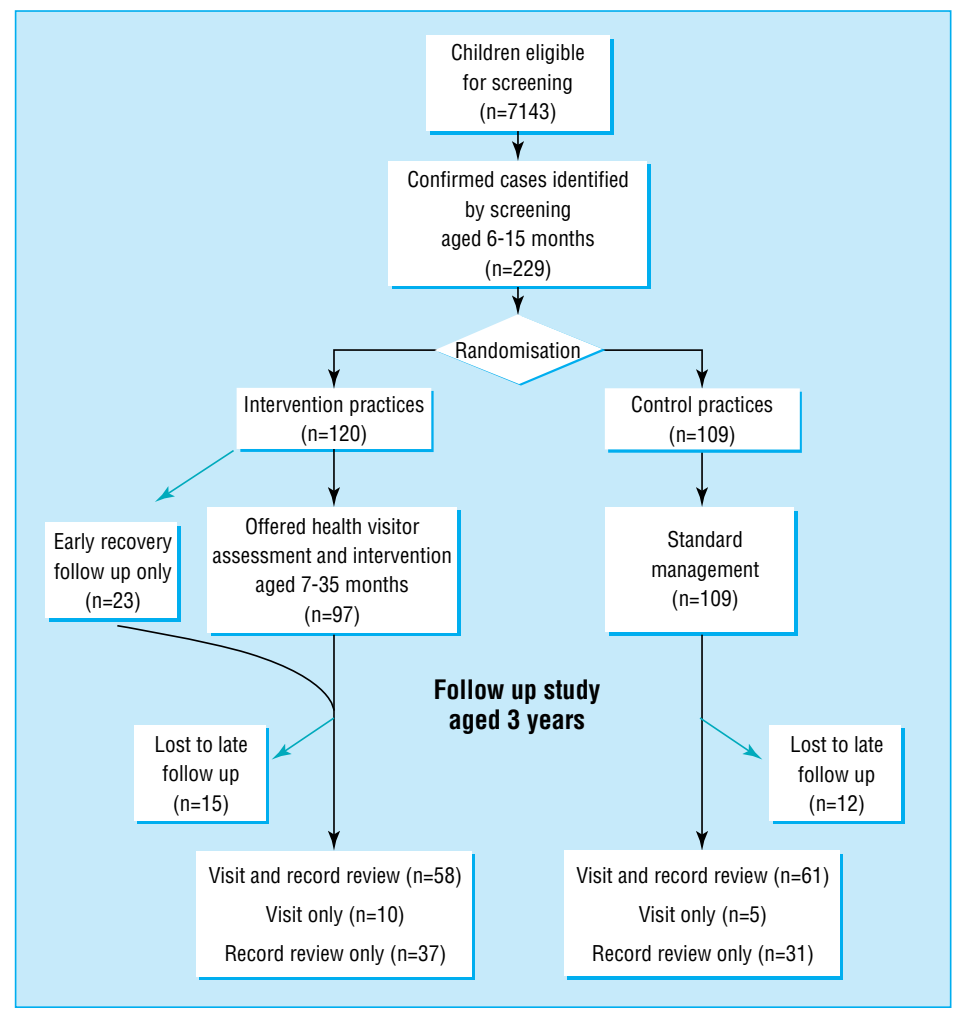

Recruitment of subjects and their progress through programme

(range 7-35) months. This assessment documented family information and the child's medical and dietary history. As the programme was designed to reflect everyday service conditions, subsequent input was only provided if deemed appropriate by the health visitor and if agreed by the family. At the outset the extra management largely consisted of providing a definitive diagnosis of failure to thrive and encouraging health visitors to look for dietary problems. At the close of recruitment, however, a programme involving staged dietetic, paediatric, and social work input was available. ${ }^{8}$

Overall, dietician input was accepted by $78(80 \%)$ families. Once the families had completed a food diary for 3 days they were usually visited by the dietician, with the health visitor when special advice was offered. Occasionally advice was relayed by the health visitor. Unless there was active hospital involvement (16 (16\%) cases) a medical examination by the project paediatrician was offered. This was taken up by $60 / 81(74 \%)$ of the families. After this the health visitor monitored the family and forwarded weights to the project team until the infant had recovered. In persisting cases (about one third) the health visitors joined team meetings to discuss future management. In $16(16 \%)$ children a referral was made for social work assessment either by social services or, later in the study, by a dedicated social worker; five others had already had social worker involvement at the time of identification.

\section{Children in control practices}

The records of the 109 children identified in control practices were checked by an independent research assistant approximately annually during the study. This assistant then retrieved weights and medical information without notifying the health visitors. The control health visitors received no additional training or support and continued routine weighing of infants in the baby clinic. If they were concerned about any infant they were referred in a conventional manner.

\section{Outcome study}

A year after the close of recruitment all the children were traced by a research nurse. The nurse offered a home visit when the child was aged over 3 years to collect basic demographic and medical information, as well as the parents' opinions, using a structured interview. The infants' weight and height, and parental heights, were measured using portable electronic scales and a Leicester height measure. Any weights in personal child health records were transcribed. For all children, clinic and primary care records were reviewed, as well as hospital notes where necessary, to extract all recorded weights and medical information. The Newcastle ethics committee approved both the trial and the outcome study.

\section{Analysis}

Initial power calculations suggested that with 90\% uptake there would be $90 \%$ power to detect a difference of $0.4 \mathrm{SD}$ in weight or height. The growth data were transformed into SD scores compared with national standards, ${ }^{9}$ except for a child with Down's syndrome, when the Down's standard was used. The prestated outcome measures were height and weight and number of routine follow up weights. Univariate comparisons were calculated by $t$ test and $\chi^{2}$ analysis. The role of potential covariates was explored using linear regression specified as a two level model (practice and individual) using the software package MLn. ${ }^{10}$

\section{Results}

At follow up beyond age 3 years, records were reviewed for $95(79 \%)$ children in the intervention group and 92 $(84 \%)$ controls. The last weights recorded (including those collected at the home visit) were beyond the age of 3 years in $74(62 \%)$ children in the intervention group and $65(60 \%)$ controls, and beyond 2 years in 85 $(71 \%)$ children in the intervention group and $72(66 \%)$ controls.

Both groups had shown early onset of failure to thrive, crossing the screening threshold at around 6 months (table 1). The screening weights for controls were collected slightly later, possibly because health visitors were aware that no clinical input would result. By this time there was a longer mean fall (thrive index) in weight. Both groups, however, reached the same lowest points at similar ages, suggesting that this represented the same underlying growth trajectory (table 1).

As would be expected from the study protocol, 92 $(97 \%)$ of the intervention children whose records were reviewed had more than three routine weights after their screening weight. Controls, however, had far fewer weights, with $15(16 \%)$ having none after the screening weight, five of whom had had severe failure to thrive when last measured (thrive index $<-2.0$ ). A further $31(34 \%)$ controls had only one or two subsequent routine weights, of whom 22 still met the screening criteria for failure to thrive when last weighed.

Only 10 cases of major organic disease were found (five in the intervention group and five controls) while 
Table 1 Baseline characteristics of families in intervention and control groups

\begin{tabular}{|c|c|c|c|c|c|}
\hline Variable & Intervention group & Control group & Mean difference & 95\% Cl difference & $P$ value ${ }^{*}$ \\
\hline No in cohort & 120 & 109 & & & \\
\hline Birthweight (SD score) $\dagger$ & -0.43 & -0.29 & -0.15 & -0.45 to 0.16 & 0.34 \\
\hline Age fell below screening threshold (months) ${ }^{\ddagger}$ & 7.0 & 7.2 & -0.19 & -1.3 to 0.88 & 0.72 \\
\hline Age at screening weight (months) & 10.8 & 12.0 & -1.2 & -2.5 to 0.11 & 0.07 \\
\hline Thrive index at screen & -1.7 & -1.9 & 0.12 & -0.02 to 0.23 & 0.09 \\
\hline Age at lowest recorded thrive index (months) & 15.9 & 15.1 & 0.80 & -1.72 to 3.3 & 0.54 \\
\hline Lowest recorded thrive index & -2.2 & -2.2 & 0.008 & -0.16 to 0.18 & 0.93 \\
\hline No of males $(\%)$ & $64(72)$ & $54(46)$ & & & $0.57 \S$ \\
\hline Ever below 2nd weight centile & $86(72)$ & $76(70)$ & & & $0.74 \S$ \\
\hline \multicolumn{6}{|l|}{ Home interviews: } \\
\hline No of families interviewed & 68 & 66 & & & \\
\hline Age at lowest recorded thrive index (months) & 13.5 & 16.6 & -3.0 & -6.3 to 0.2 & 0.06 \\
\hline Lowest recorded thrive index & -2.0 & -2.1 & 0.07 & -0.12 to 0.26 & 0.46 \\
\hline \multicolumn{6}{|l|}{ Family status: } \\
\hline No car & $25(37)$ & $28(44)$ & & & $0.45 \S$ \\
\hline No employed parent & $20(30)$ & $22(34)$ & & & $0.62 \S$ \\
\hline Rented housing & $29(43)$ & $35(54)$ & & & $0.22 \S$ \\
\hline
\end{tabular}

${ }^{*} t$ test unless stated otherwise.

†Information available for 110 intervention, 100 controls.

$\ddagger$ Calculated by interpolation between last weight age above screening threshold and first weight age below.

$\S \chi^{2}$ test.

$15(13 \%)$ children in the intervention group and 12 (11\%) controls had minor but possibly contributory conditions. Eighteen (15\%) children in the intervention group and $14(13 \%)$ controls had been seen at hospital for relevant organic conditions, and $15(13 \%)$ children in the intervention group and $24(22 \%)$ controls were seen solely for investigation of their failure to thrive, where input varied from one or two outpatient visits to prolonged admission.

Sixty eight $(57 \%)$ infants in the intervention group and $66(61 \%)$ controls were visited at home by the research nurse at a mean age of 45.2 months (range 34.5-55.1 months). The low response was largely due to non-consent (38 intervention; 34 controls). Two children in the intervention group had died (meningococcal septicaemia and hepatoma) and three families in the intervention group and one in the control group were not approached for various practical reasons such as pending care proceedings or maternal illness. Nine $(7.5 \%)$ families in the intervention group and eight $(7.3 \%)$ in the control group had moved away or were untraceable. Those infants visited, however, were of similar severity to the cohort as a whole (table 1), and children in both the intervention and the control group had similar initial growth and social characteristics.

Anthropometry at this visit showed that both groups had caught up with their weight gain, but children in the intervention group were significantly nearer to their expected weight, a difference little affected by adjustment for initial severity and age of assessment. Age and severity at screening proved not to be independently predictive. The children in the intervention group were also significantly taller, but after adjustment for parental height this difference did not attain statistical significance (table 2). When the last available weights for all children in the cohort were also compared (heights had not been collected consistently) these similarly showed a significant effect of intervention, which persisted after adjustment for initial severity and differing length of follow up (table 2). At last follow up, 91 (76\%) children in the intervention group and $60(55 \%)$ controls had recovered to above the screening threshold $\left(\mathrm{P}<0.001, \chi^{2}\right)$.
Eliciting opinions at the home visit about the service received was not straightforward, as 10/68 (15\%) parents in the intervention group and 19/66 (29\%) controls were unaware of any previous problem with feeding or growth $\left(\mathrm{P}=0.048, \chi^{2}\right)$. Mean parental ratings were, however, similar for both groups for health visiting input and the worry generated by weight monitoring, while parents in the intervention group rated their child's appetite as currently significantly better (table 3 ).

\section{Discussion}

This study suggests that, compared with conventional management, a treatment programme for failure to thrive delivered by health visitors using strict diagnostic criteria and assessment protocols, with limited additional support, results in a weight gain of around half an intercentile space using UK charts, equivalent to about $550 \mathrm{~g}$. This was despite only just over half of the intervention group receiving the full programme, because a fifth showed prior spontaneous recovery and another quarter exercised their right to decline aspects of the programme. The fairly low levels of compliance

Table 2 Results of anthropometry at home visit and last follow up

\begin{tabular}{lccccc} 
& $\begin{array}{c}\text { Intervention } \\
\text { group }\end{array}$ & $\begin{array}{c}\text { Control } \\
\text { group }\end{array}$ & P value* $^{*}$ & $\begin{array}{c}\text { Adjusted } \\
\text { mean } \\
\text { difference }\end{array}$ & $\begin{array}{c}\text { 95\% CI } \\
\text { difference }\end{array}$ \\
\hline No at home visitł & 68 & 65 & & & \\
\hline Age (months) & 44.3 & 46.1 & 0.01 & & \\
\hline Weight (SD score) & -0.93 & -1.29 & 0.044 & & \\
\hline Weight deficit & -0.54 & -0.90 & 0.016 & 0.33 & 0.02 to 0.64 \\
\hline Height (SD score) & -0.79 & -1.13 & 0.034 & & \\
\hline Height deficit" & -0.28 & -0.58 & 0.061 & 0.31 & -0.12 to 0.72 \\
\hline No at last follow up & 120 & 109 & & & \\
\hline Age (months) & 40.6 & 36.8 & 0.029 & & \\
\hline Weight (SD score) & -1.16 & -1.49 & 0.019 & & \\
\hline Weight deficit & -0.82 & -1.17 & 0.005 & 0.28 & 0.08 to 0.49 \\
\hline
\end{tabular}

${ }^{*} t$ test.

†Two level model (practice and individual) adjusted for thrive index at lowest point and age at assessment. $\neq 0$ ccasional measurements were not available: number of children in intervention group vary from 67-68, and for controls from 60-65.

§Adjusted for early weight=thrive index.

ๆAdjusted for parental height: deficit=height SD score minus mid-parental SD score. 
Table 3 Parents' ratings at home interview of service received, and perceptions of child's early problems using Likert scales. Values are means (SD)

\begin{tabular}{|c|c|c|c|}
\hline & Intervention group & Control group & $P$ value* \\
\hline Service received from health visitor ( $1=$ bad, $5=$ excellent) & $4.1(0.96)$ & $3.8(1.1)$ & 0.11 \\
\hline How often saw health visitor (1=very worried, $5=$ exciting) & $3.4(0.98)$ & $3.2(0.98)$ & 0.15 \\
\hline How did you feel about getting your child weighed? (1=very worried, $2=e x c i t e d)$ & $2.7(1.6)$ & $2.9(1.2)$ & 0.62 \\
\hline \multicolumn{4}{|l|}{ How would you describe your child's appetite (1=very poor, $5=$ =eats all the time): } \\
\hline At one year? & $2.5(1.7)$ & $2.9(1.9)$ & 0.17 \\
\hline At time of interview? & $3.4(1.6)$ & $2.9(2.0)$ & 0.03 \\
\hline Total† & 68 & 66 & \\
\hline
\end{tabular}

†Up to one case and three control responses missing for individual questions.

with the follow up home visit were also disappointing, but compliance rates were similar in both arms, and those interviewed were representative of the original group. It is fortunate, however, that routine follow up weights were also retrieved for a high proportion of the group, which also showed a significant treatment benefit.

The severity of failure to thrive found in this cohort was similar to previous population studies, as was the tendency to spontaneous recovery, ${ }^{3}$ but previous randomised trials of similar interventions have shown largely null results. ${ }^{11-13}$ However, previous trials relied on referred cases, with some treatment offered to all. Because we used population screening we were able to simply track the control group through the conventional process of identification and referral without modifying their management. This approach, however, limits the availability of information on both the progress of the infant and the management they receive. We do know that while a third of infants were referred to hospital, it seems likely that another third were not recognised as failing to thrive; weighing ceased shortly after the screening weight, before recovery, for a third of children in the control group and a third of parents in the control group were unaware of any earlier problems. This is consistent with Batchelor's finding that only $50 \%$ of children below the 3rd weight centile were known to health visitors. ${ }^{14}$ Much of the increased effectiveness in the intervention group could be because more of the cases had been recognised and offered any treatment. A substantial number of children both in the intervention $(\mathrm{n}=33)$ and in the control $(n=38)$ group were seen at hospital despite low levels of organic disease. If such referrals could be diverted the savings would justify the limited additional dietetic and paediatric input required to support management by health visitors.

\section{Key messages}

- Supporting health visitors in the recognition and management of children under 2 years of age with failure to thrive resulted in closer follow up and significantly better long term weight and height gain than conventional hospital based management

- In the control group, $15-30 \%$ of cases of failure to thrive remained unrecognised by the clinical team

- Although a third of cases of failure to thrive were seen at hospital, only $5 \%$ had major organic disease
This trial presented a huge challenge methodologically and logistically and it inevitably has its limitations. However, it represents a rare example both of a trial of any treatment in failure to thrive and of the effectiveness of any management by health visitors. We suggest that these are encouraging results that would justify this approach being more widely adopted, and that this model of health visiting practice might also be applied to the management of other conditions.

We thank the intervention health visitors, the staff of the Parkin Service, Lynette Swanson, the National Society for the Prevention of Cruelty to Children, Tony Waterston, and $\mathrm{Al}$ Aynsley Green for their input to the study, and Edmund Hey and Tim Cole for their comments on successive drafts of the paper. The service was named after Michael Parkin who initiated the study before his untimely death.

Contributors: CMW ran the study from its inception and has taken the lead role in design, analysis, and writing the paper; she will act as guarantor for the paper. JC worked on the follow up study only, but took lead responsibility for this phase, including questionnaire design and data collection and entry. EB was primarily involved in the planning and execution of the intervention study as well as the identification and tracking of cases and controls. SJ acted as mentor and adviser on the methodology, and read and commented on successive drafts of the manuscript.

Funding: Wellcome Trust, Newcastle Hospitals Special Trustees, and Henry Smith Charity

Conflict of interest: None.

1 Skuse D. Non-organic failure to thrive: a reappraisal. Arch Dis Child 1985;60:173-8.

2 Corbett S, Drewett R, Wright C. Does a fall down a centile chart matter? The growth and developmental sequelae of mild failure to thrive. Acta Paediatr 1996;85:1278-83.

3 Skuse D, Pickles A, Wolke D, Reilly S. Postnatal growth and mental development: evidence for a "sensitive period". J Child Psychol Psychiat 1994;35:521-45

4 Barker D, Winter P, Osmond C, Margetts B, Simmonds S. Weight in infancy and death from ischaemic heart disease. Lancet 1989;i:577-80.

5 Bithoney WG, McJunkin J, Mchalek J, Egan H, Snyder J, Munier A. Prospective evaluation of weight gain in both non-organic and organic failure to thrive children: an outpatient trial of a multidisciplinary team intervention strategy. Dev Behav Pediatr 1989;10:27-31.

6 Kristiansson B, Fallstrom SP. Growth at age of 4 years subsequent to early failure to thrive. Child Abuse Negl 1987;11:35-40.

7 Wright CM, Waterston A, Matthews JNS, Aynsley-Green A. What is the normal rate of weight gain in infancy? Acta Paediatr 1994;83:351-6.

8 Wright CM, Talbot E. Screening for failure to thrive-what are we looking for? Child care, Health Dev 1996;22:223-34.

9 Freeman JV, Cole TJ, Chinn S, Jones PRM, White EM, Preece MA. Cross sectional stature and weight reference curves for the UK, 1990. Arch Dis Child 1995;73:17-24

10 Woodehouse G. Multilevel modelling applications-a guide for users of MLn. London: Institute of Education, 1996.

11 Drotar D, Sturm L. Prediction of intellectual development in young children with early histories of non-organic failure to thrive. J Pediatr Psychol $1988 ; 13: 281-96$

12 Haynes C, Cutler C, Gray J, Kempe R. Hospitalised cases of non-organic failure to thrive: the scope of the problem and short term lay health visitor intervention. Child Abuse Negl 1984;8:229-42.

13 Black MM, Dubowitz H, Hutcheson J, Berenson-Howard J, Starr RH. A randomized clinical trial of home intervention for children with failure to thrive. Pediatrics 1995;95:807-14.

14 Batchelor J, Kerslake A. Failure to find failure to thrive. London: Whiting and Bush, 1990.

(Accepted 27 February 1998) 